\title{
Influência da suplementação concentrada e da categoria animal no hemograma de ovinos da raça Morada Nova
}

\author{
[Influence of concentrate supplementation and the animal category in the \\ hemogram of Morada Nova sheep] \\ L.R. Bezerra ${ }^{1}$, J.N.C. Torreão ${ }^{1}$, C.A.T. Marques ${ }^{1}$, L.P. Machado ${ }^{1}$, \\ M.J. Araújo ${ }^{1}$, A.M.S. Veiga ${ }^{2}$ \\ ${ }^{1}$ Universidade Federal do Piauí - Bom Jesus, PI \\ ${ }^{2}$ Aluno de graduação - Universidade Federal do Piauí - Bom Jesus, PI
}

\begin{abstract}
RESUMO
Objetivou-se avaliar a influência do nível de suplementação com concentrado sobre o perfil hematológico de ovelhas Morada Nova no terço final da gestação e puerpério, bem como comparar os valores obtidos em diferentes categorias (fêmeas em gestação, puerpério e cordeiros). Utilizaram-se 11 ovelhas, aos 75 últimos dias de gestação e nos primeiros 75 dias de lactação, e oito cordeiros progênie das ovelhas, distribuídas em delineamento inteiramente casualizado em arranjo de parcelas subdivididas no tempo. Durante o período experimental, os animais permaneceram em pastagem de Andropogon gayanus, sendo recolhidos ao final da tarde, quando recebiam suplementação concentrada com 19,17\% de proteína bruta. As amostras de sangue foram colhidas desde o $75^{\circ}$ dia de gestação até o desmame, aos 75 dias de lactação, a cada quatorze dias. O sangue foi colhido sempre pela manhã, antes de os animais serem liberados para o pasto, por punção da veia jugular, para a realização do hemograma. Os diferentes níveis de suplementação não influenciaram $(\mathrm{P}>0,05)$ o perfil eritrocitário e leucocitário das ovelhas. A categoria animal influenciou $(\mathrm{P}<0,05)$ o teor de hemoglobina e o número de eritrócitos. Os valores médios de hemoglobina não difeririam $(\mathrm{P}>0,05)$ entre fêmeas gestantes $(7,74 \mathrm{~g} / \mathrm{dL})$ e puerperais $(7,67 \mathrm{~g} / \mathrm{dL})$, bem como a contagem total de hemácias dos cordeiros $\left(8,14 \times 10^{6} / \mu \mathrm{L}\right)$ e das fêmeas em puerpério $(9,16 \mathrm{x}$ $10^{6} / \mu \mathrm{L}$ ). Os valores médios do hematócrito, volume corpuscular médio, concentração de hemoglobina corpuscular média e proteína total não diferiram estatisticamente $(\mathrm{P}>0,05)$ entre as ovelhas; no entanto, observaram-se maiores níveis para os cordeiros. O número de leucócitos totais foram superiores $(\mathrm{P}<0,05)$ nas ovelhas gestantes e puerperais em relação aos cordeiros. A suplementação concentrada não influenciou o perfil hematológico dos animais, porém a categoria animal exerceu influência sobre os parâmetros hematológicos eritrocitários e leucocitários.
\end{abstract}

Palavras-chave: hemoglobina, neutrófilos, ovinos nativos, suplementação

\begin{abstract}
This research was carried out to evaluate the influence of supplementation with concentrate on hematological profile of Morada Nova sheep in last third of pregnancy and postpartum, as well as comparing the values obtained in different categories (pregnant females, postpartum, and lambs). Eleven ewes it the last 75 days of pregnancy and the first 75 days of lactation and eight lambs born from the ewes allotted in completely randomized design and split-plot arrangement in time were used. During the experimental period, the animals remained in Andropogon gayanus pasture. Late in the afternoon they returned to the center of management to receive the concentrate supplementation with $19.17 \%$ of crud protein. Blood samples were collected from the 75 th day of pregnancy to weaning at 75 days of lactation, every fourteen days. Blood samples were taken always in the morning, before the animals were released
\end{abstract}

Recebido em 22 de maio de 2012

Aceito em 13 de junho de 2013

E-mail: leilson@ufpi.edu.br 
into the pasture, by puncturing the jugular vein, for complete blood count. Neither the erythrocyte profile nor the leukocyte profile was affected by the different levels of supplementation $(P>0.05)$. The animal category had a significant effect $(P<0.05)$ on hemoglobin and erythrocyte number. The mean hemoglobin values did not differ $(P>0.05)$ between pregnant ewes $(7.74 \mathrm{~g} / \mathrm{dL})$ and ones in postpartum $(7.67 \mathrm{~g} / \mathrm{dL})$ as well as the total count of red blood cells of the lambs $(8.14 \times 106 / \mu \mathrm{L})$ did not differ $(P>0.05)$ from females in postpartum $(9.16 \times 106 / \mu l)$. When comparing between pregnant and postpartum ewes for the mean hematocrit values, mean corpuscular volume, mean corpuscular hemoglobin concentration and total protein did not differ $(P>0.05)$. The highest values were observed in these animals. The total white cell count was higher $(P<0.05)$ in pregnant and postpartum ewes than lambs. The concentrate supplementation did not affect the blood profile of animals, but the animal category exerted influence on erythrocyte and leukocyte hematological parameters.

Keywords: hemoglobin, neutrophils, indigenous sheep, supplementation

\section{INTRODUÇÃO}

A raça Morada Nova representa uma das principais raças nativas de ovinos deslanados do Nordeste do Brasil. Por serem animais de pequeno porte e bem adaptados às condições climáticas do semiárido, são importantes nas pequenas propriedades (Fernandes et al., 2001). Durante alguns anos esses animais foram sendo gradativamente substituídos por raças exóticas, com o objetivo de aumentar os índices produtivos. A difusão da exploração dessa espécie trouxe a necessidade de métodos para a avaliação das condições metabólico-nutricionais de ovelhas de produção, pois, nos sistemas intensivos de exploração, a ocorrência de distúrbios metabólicos nutricionais são frequentes.

A importância da hematologia como meio semiológico, auxiliando os veterinários a estabelecerem diagnósticos, firmarem prognósticos e acompanharem os tratamentos das inúmeras enfermidades que atingem os animais domésticos é reconhecida e consagrada mundialmente. Entretanto, para que esses objetivos possam ser alcançados e utilizados na plenitude, tornou-se fundamental o conhecimento dos valores de referência do hemograma dos animais sadios, bem como dos fatores causadores de suas variações (Viana et al., 2002).

Dentre os fatores que merecem destaque em relação à significativa influência dos fatores ambientais sobre o quadro hemático dos animais, estão: as diferentes condições ambientais e climáticas e a fase fisiológica por que esse animal passa. Assim, os valores obtidos para os animais criados em uma região não podem ser considerados, sem uma adequada avaliação, como padrão de referência fora dessa região (Bezerra et al., 2008). Além disso, as pesquisas com índices hemáticos direcionadas à espécie ovina na região Nordeste ainda são poucas, sobretudo referentes ao conhecimento de alterações dos constituintes hematológicos da espécie nas fases gestacionais e lactante.

Dessa forma, evidencia-se a necessidade da realização de estudos para se determinar os valores de referência do hemograma dos ovinos criados nas condições brasileiras de manejo e alimentação, bem como a avaliação dos fatores de variação sobre a crase sanguínea. Entre esses fatores, merecem destaque aqueles relacionados à gestação, à parição e ao puerpério, já que essas fases fisiológicas demandam grande quantidade de nutrientes tanto para o animal quanto para o feto que ele está gerando. Nesse sentido, com a realização deste trabalho, objetivou-se avaliar a influência do nível de suplementação no terço final de gestação e início de lactação e da categoria animal (fêmeas em gestação e puerpério e cordeiros) sobre o hemograma de ovelhas Morada Nova a pasto.

\section{MATERIAL E MÉTODOS}

O experimento foi conduzido na Unidade de Pesquisa em Pequenos Ruminantes do Campus Professora Cinobelina Elvas, da Universidade Federal do Piauí, localizada no município de Bom Jesus, PI.

Foram utilizadas 11 ovelhas pluríparas da raça Morada Nova, cobertas através de inseminação artificial. Após a inseminação, foi realizado o diagnóstico de prenhez, através de ultrassonografia transretal. Foi realizado manejo 
sanitário preventivo, com a vermifugação e vacinação contra enterotoxemia, além dos cuidados preventivos de rotina.

O período experimental foi de 150 dias, compreendendo os 75 últimos dias de gestação e os primeiros 75 dias de lactação. Durante o período experimental, as ovelhas permaneceram em piquetes de Andropogon gayanus, sendo recolhidas ao final da tarde e alocadas em baias individuais, medindo $3,75 \mathrm{~m}^{2}$, onde receberam a suplementação concentrada à base de milho moído (70\%), farelo de soja $(25 \%)$ e suplemento mineral (5\%), com base na matéria seca (Tab. 1). Os tratamentos foram formados em função do percentual de suplementação concentrada $(0,5 \%$ e $1,5 \%$ do peso vivo), formulada conforme recomendações do NRC (Nutrient..., 2007). Semanalmente, todas as ovelhas foram pesadas para o ajuste da suplementação concentrada.

Tabela 1. Composição química dos ingredientes e do concentrado experimental

\begin{tabular}{lcccccc}
\hline \multirow{2}{*}{ Ingrediente } & \multicolumn{7}{c}{ Composição química (\%MS) } \\
\cline { 2 - 7 } & $\mathrm{MS}$ & $\mathrm{PB}$ & $\mathrm{EE}$ & $\mathrm{NDT}$ & $\mathrm{Ca}$ & $\mathrm{P}$ \\
\hline Milho moído & 87,19 & 9,98 & 5,19 & 67,50 & 0,05 & 0,49 \\
Farelo de Soja & 88,48 & 48,76 & 1,75 & 80,73 & 0,33 & 0,57 \\
Suplemento Mineral & 97,91 & - & - & - & 18,00 & 13,00 \\
\hline Concentrado & 88,04 & 19,17 & 4,06 & 67,43 & 1,01 & 1,13 \\
\hline
\end{tabular}

MS: matéria seca; PB: proteína bruta; EE: extrato etéreo; NDT: nutrientes digestíveis totais; Ca: cálcio; P: fósforo.

Já os cordeiros alimentaram-se apenas do aleitamento materno até os 75 dias após o parto, quando foram apartados. Além da avaliação da influência dos níveis de suplementação, foram avaliadas três categorias de animais (fêmeas em gestação, fêmeas em puerpério e cordeiros).

Nas fêmeas, as amostras de sangue foram colhidas a cada 14 dias, a partir do $75^{\circ}$ dia de gestação até os 75 dias de lactação (momento em que os cordeiros foram desmamados), ao passo que o sangue dos cordeiros foi colhido a partir do primeiro dia de vida, também a cada 14 dias. O sangue foi colhido sempre pela manhã, antes de os animais serem liberados para o pasto, por punção da veia jugular, utilizando-se agulhas descartáveis 25 × $8 \mathrm{~mm}$ (21G) para múltipla colheita e deposição em tubos de vidro tipo vacutainer contendo $0,05 \mathrm{~mL}$ de uma solução aquosa a $10 \%$ de etileno-diamino-tetracetato de sódio (EDTA) para cada cinco $\mathrm{mL}$ de sangue colhido. As amostras de sangue foram mantidas em caixa térmica com gelo até a chegada ao Laboratório de Patologia Clínica (CPCE-UFPI), onde, num prazo de 24 horas, foi concluído o hemograma que consistiu de contagem global do número de hemácias, determinação do volume globular, teor de hemoglobina, índices hematimétricos absolutos, contagem global do número de leucócitos e contagem diferencial de leucócitos.
A contagem do número de hemácias foi realizada em câmara do tipo Neubauer modificada e, para tanto, a diluição das células foi feita utilizando-se pipeta semiautomática de 20 microlitros. Para determinação do volume globular, empregou-se a técnica do micro-hematócrito, na qual se utilizaram tubos capilares homogêneos de 75 milímetros de comprimento por um milímetro de diâmetro. A determinação do teor de hemoglobina no sangue foi feita pelo método do cianometa-hemoglobina.

Os valores obtidos com a contagem do número de hemácias, do volume globular e com a determinação do teor de hemoglobina serviram para se estabelecer os valores dos índices hematimétricos absolutos, mediante prévia digitação dos valores em aparelho específico para contagem diferencial de leucócitos.

A contagem do número total de leucócitos foi realizada em Câmara de Neubauer modificada, sendo as amostras de sangue diluídas, na proporção de 1:20, utilizando-se como solução diluidora o líquido de Turk de acordo com as recomendações de Viana et al. (2002). Com o sangue "in natura", foram distendidos dois esfregaços sanguíneos destinados à contagem diferencial de leucócitos. Esses esfregaços, após secarem, foram corados utilizando-se o corante rápido do tipo Romanowsky (Panótico Rápido LABORCLIN $^{\circledR}$ LTDA, Pinhais, Paraná, Brasil), segundo técnica padronizada para os animais por 
Viana et al. (2002). Em cada esfregaço sanguíneo foram diferenciados 100 leucócitos classificados e lidos em microscópio em aumento de 1000x, de acordo com suas características morfológicas e tintoriais, em neutrófilos com núcleo em bastonete, neutrófilos com núcleo segmentado, eosinófilos, basófilos, linfócitos e monócitos. A determinação da Proteína Plasmática Total (PPT) foi realizada por refratometria, após a centrifugação do sangue em capilar de micro-hematócrito.

O experimento foi conduzido em delineamento inteiramente casualizado. Consideraram-se os efeitos de tratamento $(0,5$ e $1,5 \%$ PV de suplementação concentrada) e o efeito de categoria (ovelhas em gestação, em puerpério e cordeiros). As variáveis sanguíneas foram avaliadas pelo arranjo em parcelas subdivididas. A parcela principal constituirá os níveis de suplementação e a parcela secundária, os períodos de colheita, com medidas repetidas no tempo. Os dados foram analisados usando o SAS (Statistical ..., 2000) -, e para comparação de médias utilizou-se o teste de Student-Newman-
Keuls, com nível de significância igual a 5\%. Este trabalho obedeceu a todos os princípios éticos nas pesquisas envolvendo animais e foi aprovado no Comitê de Bioética da UFPI com número CPCE-61/2010.

\section{RESULTADOS E DISCUSSÃO}

Os diferentes níveis de suplementação concentrada, no terço final de gestação e início de lactação, não influenciaram $(\mathrm{P}>0,05)$ o perfil eritrocitário de ovelhas da raça Morada Nova em regime de pasto (Tab. 2).

De acordo com Paes et al. (2000), os parâmetros sanguíneos têm sido utilizados mundialmente para avaliar o estado de saúde dos animais e também como indicadores de estresse calórico. Podendo, vários fatores, como espécie, sexo, idade, estado fisiológico, hora do dia, umidade relativa do ar, temperatura do ambiente e atividade muscular, provocarem alteração desses parâmetros (Birgel Júnior et al., 2001; Silva et al., 2006; Lacerda e Soto-Blanco, 2006).

Tabela 2. Influência do nível de suplementação sobre o perfil eritrocitário de ovelhas da raça Morada Nova no pré e pós-parto em regime de pasto (média \pm desvio padrão)

\begin{tabular}{|c|c|c|c|c|}
\hline \multirow{2}{*}{ Variáveis } & \multicolumn{2}{|c|}{ Nível de suplementação } & \multirow[b]{2}{*}{$\operatorname{Pr}>F$} & \multirow[b]{2}{*}{ Referência } \\
\hline & $0,5 \%$ & $1,5 \%$ & & \\
\hline Hemoglobina (g/dL) & $7,62 \pm 1,22$ & $8,42 \pm 1,85$ & 0,366 & $8-12$ \\
\hline Hematócrito (\%) & $25,58 \pm 4,00$ & $23,69 \pm 4,71$ & 0,512 & $22-38$ \\
\hline Hemácias $\left(\times 10^{6} / \mu \mathrm{L}\right)$ & $10,47 \pm 1,11$ & $9,26 \pm 2,30$ & 0,123 & $8-18$ \\
\hline $\operatorname{VCM}\left(\mu \mathrm{m}^{3}\right)$ & $26,81 \pm 4,69$ & $36,50 \pm 4,58$ & 0,081 & $28-40$ \\
\hline $\mathrm{CHCM}(\%)$ & $32,18 \pm 4,76$ & $33,08 \pm 6,74$ & 0,179 & $30-36$ \\
\hline PPT (g/dL) & $6,98 \pm 0,74$ & $6,67 \pm 1,11$ & 0,148 & $4-8$ \\
\hline
\end{tabular}

VCM: volume corpuscular médio; CHCM: concentração de hemoglobina corpuscular média; PPT: Proteína Plasmática Total.

Médias seguidas de letras distintas diferem estatisticamente $(\mathrm{P}<0,05)$ pelo teste de Student-Newman-Keuls.

${ }^{1}$ Intervalo de referência para ovinos adultos (Kramer, 2006).

Com a redução da ingestão de alimentos em virtude do incremento calórico produzido pela digestão da fibra, os animais entram em balanço energético negativo, fazendo uso de suas reservas corporais e desencadeando alteração nos seus parâmetros hematológicos. Apesar de alguns autores afirmarem que a alimentação inadequada durante a gestação e lactação afeta os parâmetros hematológicos, o que se observa é que, quando as exigências são atendidas, as interferências nos parâmetros são insignificantes. Quando os requerimentos nutricionais de ovelhas no pré e no pós-parto não são atendidos, os níveis de hemoglobina e o hematócrito apresentam-se diminuídos. Da mesma forma, a deficiência de energia na dieta também está relacionada com baixos níveis de hemoglobina (Bezerra et al., 2008). Portanto, com base no exposto, acredita-se que os animais deste estudo, mesmo submetidos ao menor nível de suplementação, tiveram suas exigências nutricionais atendidas, uma vez que o perfil eritrocitário não foi alterado e se manteve dentro dos limites de referência para ovinos adultos conforme citado por Kramer (2006) (Tab. 2). 
Silva et al. (2006), ao estudarem o efeito da suplementação lipídica em caprinos, não observaram redução do número de eritrócitos, hemoglobina e do volume globular, porém afirmaram que o evento poderá ocorrer em virtude da hemoconcentração decorrente da redução da ingestão de alimentos e água.

Pela ocorrência de erros inerentes às tentativas do cálculo de valores médios e desvios padrão da média a partir de valores apresentados em porcentagens, optou-se, na apresentação dos resultados da presente pesquisa, pela utilização dos valores absolutos, aceitando-se, portanto, as recomendações de Viana et al. (2002), de que essa seria a forma mais representativa para a apresentação dos resultados relacionados ao leucograma.

Conforme apresentado na Tab. 3, a suplementação concentrada não influenciou ( $\mathrm{P}>0,05)$ a contagem de leucócitos totais, número de neutrófilos, de eosinófilos, de monócitos, de linfócitos e de basófilos das ovelhas no presente estudo.

Tabela 3. Influência do nível de suplementação sobre o perfil leucocitário de ovelhas da raça Morada Nova no pré e pós-parto em regime de pasto (média \pm desvio padrão)

\begin{tabular}{|c|c|c|c|c|}
\hline \multirow{2}{*}{ Variáveis } & \multicolumn{2}{|c|}{ Nível de suplementação } & \multirow[b]{2}{*}{$\operatorname{Pr}>F$} & \multirow[b]{2}{*}{ Referência $^{1}$} \\
\hline & $0,5 \%$ & $1,5 \%$ & & \\
\hline Leucócitos $(/ \mu \mathrm{L})$ & $8254,9 \pm 2609,48$ & $8521,6 \pm 2392,05$ & 0,459 & $4000-12000$ \\
\hline Neutrófilos $(/ \mu \mathrm{L})$ & $3532,2 \pm 1569,92$ & $3603,1 \pm 1293,85$ & 0,719 & $700-6000$ \\
\hline Eosinófilos $(/ \mu \mathrm{L})$ & $414,82 \pm 302,25$ & $453,47 \pm 260,86$ & 0,529 & $0-1000$ \\
\hline Monócitos $(/ \mu \mathrm{L})$ & $226,95 \pm 141,64$ & $203,37 \pm 106,91$ & 0,510 & $0-750$ \\
\hline Linfócitos $(/ \mu \mathrm{L})$ & $4095,5 \pm 1206,62$ & $4340,4 \pm 1390,97$ & 0,477 & $2000-9000$ \\
\hline Basófilos $(/ \mu \mathrm{L})$ & $64,28 \pm 19,17$ & $61,65 \pm 21,21$ & 0,463 & $0-300$ \\
\hline
\end{tabular}

Médias seguidas de letras distintas diferem estatisticamente $(\mathrm{P}<0,05)$ pelo teste de Student-Newman-Keuls.

${ }^{1}$ Intervalo de referência para ovinos adultos (Kramer, 2006).

Analisando a literatura mundial, existe uma concordância relativa aos efeitos de fatores como o parto, a gestação, a realização de implantação de cânula ruminal, orquiectomia e processos inflamatórios sobre alterações do quadro leucocitário (Viana et al., 2002; Bezerra et al., 2008; Fatorreto, 2009; Luz et al., 2010; Sousa et al., 2011). No entanto, trabalhos que avaliem a influência da dieta sobre essas varáveis são escassos, e menos ainda em se tratando de animais nativos, como é o caso de animais da raça Morada Nova.

A categoria animal influenciou $(\mathrm{P}<0,05)$ os teores de hemoglobina e o número de eritrócitos, observando os maiores valores de hemoglobina $(8,91 \mathrm{~g} / \mathrm{dL})$ para os cordeiros, e de contagem total de hemácias $\left(11,46 \times 10^{6} / \mu \mathrm{L}\right)$ para fêmeas gestantes (Tab. 4).

Tabela 4. Influência da categoria animal (fêmea em gestação, fêmea em puerpério e cordeiros) sobre o perfil eritrocitário de ovelhas da raça Morada Nova a pasto e suas crias (média \pm desvio padrão)

\begin{tabular}{lcccc}
\multirow{2}{*}{\multicolumn{1}{c}{ Variáveis }} & \multicolumn{3}{c}{ Categoria } & Pr>F \\
\cline { 2 - 4 } & Gestação & Puerpério & Cordeiro & 0,0009 \\
Hemoglobina $(\mathrm{g} / \mathrm{dL})$ & $7,74 \pm 1,56 \mathrm{~b}$ & $7,67 \pm 1,34 \mathrm{~b}$ & $8,91 \pm 1,30 \mathrm{a}$ & 0,4855 \\
Hematócrito $(\%)$ & $24,17 \pm 3,94$ & $25,14 \pm 4,34$ & $24,92 \pm 3,90$ & 0,0023 \\
Hemácias $\left(x 10^{6} / \mu \mathrm{L}\right)$ & $11,46 \pm 1,29 \mathrm{a}$ & $9,36 \pm 1,17 \mathrm{~b}$ & $8,14 \pm 2,42 \mathrm{~b}$ & 0,0181 \\
VCM $\left(\mu \mathrm{m}^{3}\right)$ & $25,89 \pm 4,26 \mathrm{~b}$ & $27,05 \pm 4,77 \mathrm{~b}$ & $47,03 \pm 4,20 \mathrm{a}$ & 0,0001 \\
CHCM $(\%)$ & $31,99 \pm 3,80 \mathrm{~b}$ & $31,02 \pm 5,73 \mathrm{~b}$ & $36,10 \pm 4,54 \mathrm{a}$ & $<0,0001$ \\
PPT $(\mathrm{g} / \mathrm{dL})$ & $6,66 \pm 0,55 \mathrm{~b}$ & $6,68 \pm 0,64 \mathrm{~b}$ & $7,40 \pm 0,80 \mathrm{a}$ & \\
\hline
\end{tabular}

VCM: volume corpuscular médio; CHCM: concentração de hemoglobina corpuscular média; PPT: Proteína Plasmática Total.

Médias seguidas de letras distintas diferem estatisticamente $(\mathrm{P}<0,05)$ pelo teste de Student-Newman-Keuls. 
Não foi observada diferença $(\mathrm{P}>0,05)$ nos valores médios de hemoglobina entres fêmeas gestantes $(7,74 \mathrm{~g} / \mathrm{dL})$ e puerperais $(7,67 \mathrm{~g} / \mathrm{dL})$. Também não se observou diferença $(\mathrm{P}>0,05)$ entre a contagem total de hemácias dos cordeiros $\left(8,14 \times 10^{6} / \mu \mathrm{L}\right)$ e das fêmeas em puerpério $\left(9,16 \times 10^{6} / \mu \mathrm{L}\right)$. A redução do eritrograma durante o estágio final da gestação tem sido interpretada como efeito da hemodiluição resultante do aumento do volume plasmático.

Segundo El-Sherif e Assad (2001), em ambiente semiárido, os parâmetros eritrocitários aumentam significativamente, alcançando valores máximos durante o parto e diminuindo após esse período. Neste experimento, observou-se que esse aumento influenciou os maiores valores encontrados na fase de gestação, enquanto a redução ocorrida após o parto foi consequência dos menores valores encontrados nessa fase fisiológica.

Os valores médios do hematócrito, volume corpuscular médio, concentração de hemoglobina corpuscular média e proteína não diferiram estatisticamente $(\mathrm{P}>0,05)$ entre as ovelhas (Tab. 4). Entretanto, quando se comparou ovelhas prenhes e puerperais com os cordeiros, observaram-se os maiores níveis nos cordeiros. Brito et al. (2006) não observaram diferença nos constituintes hematológicos entre ovelhas prenhes e gestantes, apesar de evidenciar que o hematócrito diminui com o avanço da gestação. Os autores relataram que as variações dos metabólitos sanguíneos ocorrem nos períodos de final da gestação e início da lactação, que correspondem aos momentos de maior exigência metabólica.

Em relação ao quadro leucocitário (Tab. 5), observou-se influência da categoria $(\mathrm{P}<0,05)$ na contagem total de leucócitos e nos valores absolutos de neutrófilos, linfócitos e monócitos.

O número de leucócitos totais encontra-se significativamente aumentado $(\mathrm{P}<0,05)$ nas ovelhas gestantes e puerperais em relação aos cordeiros, principalmente devido ao aumento de neutrófilos. Em um estudo com cabras Saanen, Viana et al. (2002) observaram que o leucograma sofreu influência da gestação, sendo o quadro leucocitário caracterizado por uma diminuição gradual do número de leucócitos com o avançar da gestação.

Tabela 5. Influência da categoria animal (gestação, puerpério e cordeiro) sobre o perfil leucocitário de ovelhas da raça Morada Nova a pasto e suas crias (média \pm desvio padrão)

\begin{tabular}{lcccc}
\hline \multirow{2}{*}{ Variáveis } & \multicolumn{3}{c}{ Categoria } & Pr $>$ F \\
\cline { 2 - 4 } & Gestação & Puerpério & Cordeiro & $<0,0001$ \\
\hline Leucócitos $(/ \mu \mathrm{L})$ & $9006,0 \pm 2967,91 \mathrm{a}$ & $8888,5 \pm 1647,48 \mathrm{a}$ & $6478,8 \pm 1407,34 \mathrm{~b}$ & $<0,0001$ \\
Neutrófilos $(/ \mu \mathrm{L})$ & $4137,0 \pm 1679,47 \mathrm{a}$ & $3632,5 \pm 1122,44 \mathrm{a}$ & $2466,5 \pm 614,73 \mathrm{~b}$ & 0,1613 \\
Eosinófilos $(/ \mu \mathrm{L})$ & $497,4 \pm 374,53$ & $388,3 \pm 249,34$ & $389,3 \pm 142,22$ & 0,0057 \\
Monócitos $(/ \mu \mathrm{L})$ & $170,3 \pm 106,74 \mathrm{~b}$ & $253,8 \pm 148,77 \mathrm{a}$ & $236,3 \pm 96,18 \mathrm{a}$ & 0,0010 \\
Linfócitos $(/ \mu \mathrm{L})$ & $4327,8 \pm 1535,00 \mathrm{a}$ & $4569,1 \pm 1064,89 \mathrm{a}$ & $3426,9 \pm 720,68 \mathrm{~b}$ & 0,2330 \\
Basófilos $(/ \mu \mathrm{L})$ & $33,6 \pm 20,16$ & $34,3 \pm 19,54$ & $34,17 \pm 20,33$ & \\
\hline
\end{tabular}

Médias seguidas de letras distintas diferem estatisticamente $(\mathrm{P}<0,05)$ pelo teste de Student-Newman-Keuls.

As variações do número de leucócitos ocorreram em decorrência do comportamento observado para o número absoluto de linfócitos que diminuiu com a evolução da gestação, tornando o quadro leucocitário predominantemente neutrofílico na fase final da gestação e no puerpério (Viana et al., 2002) Neste experimento, observou-se uma neutrofilia $(\mathrm{P}<0,05)$ em relação aos cordeiros tanto no período gestacional quanto lactacional, porém essas duas fases não diferiram entre si $(\mathrm{P}>0,05) \mathrm{e}$ os valores permaneceram dentro da referência para ovinos (Kramer, 2006). As alterações leucocitárias observadas são consistentes com as alterações mediadas pelo ACTH e podem estar associadas à idade.

\section{CONCLUSÕES}

O perfil hematológico analisado demonstrou não sofrer influência do nível de suplementação quando se comparou ovelhas prenhes e puerperais. Porém, quando comparadas as três categorias, observou-se que as maiores variações dos metabólitos sanguíneos ocorrem entre cordeiros e as duas categoria de fêmeas 
estudadas. Os fatos anteriormente discutidos evidenciam, de forma notória, a necessidade da realização de estudos para se determinar os valores de referência do hemograma de animais de produção.

\section{REFERÊNCIAS}

BEZERRA, L.R.; FERREIRA, A.F.; CAMBOIM, E.K.A. et al. Perfil hematológico de cabras clinicamente sadias criadas no Cariri paraibano. Cienc. Agrotecnol., v.32, p.955-960, 2008.

BIRGEL JÚNIOR, E.H.; D ANGELINO, J.L.; BENESI, F.J.; BIRGEL, E.H. Valores de referência do eritrograma de bovinos da raça Jersey criados no estado de São Paulo. Arq. Bras. Med. Vet. Zootec., v.53, p.1-9, 2001.

BRITO, M.A.; GONZÁLEZ, F.D.; RIBEIRO, L.A. et al. Composição do sangue e do leite em ovinos leiteiros do sul do Brasil: variações na gestação e na lactação. Cienc. Rural, v.36, p.942-948, 2006.

EL-SHERIF, M.M.; ASSAD, F. Changes in some blood constituents of Barki ewes during pregnancy and lactation under semi arid conditions. Small Ruminant Res., v.40, p.269-277, 2001.

FATORRETO, B. Perfil inflamatório e cicatricial em ovinos submetidos á orquiectomia. An. Pr. In. Cien. Dis., v.12, p.43-55, 2009.

FERNANDES, A.A.O; BUCHANAN, D.; SELAIVEVILLARROEL, A.B. Avaliação dos Fatores Ambientais no Desenvolvimento Corporal de Cordeiros Deslanados da Raça Morada Nova. Rev. Bras. Zootec., v.30, p.1460-1465, 2001.

KRAMER, J.W. Normal hematology of cattle, sheep, and goats. In: FELDMAN, B.F.; ZINKL, J.G.; JAIN, N.C. (Ed.) Schalm's veterinary hematology, 5.ed. Ames: Blackwell, 2006. p.1075-1084.
LACERDA, R.M.; SOTO-BLANCO, B. Determinação das variantes de hemoglobina em ovinos mestiços Santa Inês. Caatinga, v.19, p.345349, 2006

LUZ, D.O.; LACERDA, R.M.; BARRETO JÚNIOR, R.A.; SOTO-BLANCO, B. Eritrograma e variantes de hemoglobina em caprinos da raça Canindé. Arq. Bras. Med. Vet. Zootec., v.62, p.208-210, 2010.

NUTRIENT Requirements of small Ruminants: Sheep, Goats, Cervids and New Words Camelids. Washington, DC: National Academy Press, 2007. $384 \mathrm{p}$.

PAES, P.R.; BARIONI, G.; FONTEQUE, J.R. Comparação dos valores hematológicos entre caprinos fêmeas da raça Parda Alpina de diferentes faixas etárias. Vet. Notícias, v.6, p.43-49, 2000.

SILVA, G.A.; SOUZA, B.B.; ALFARO, C.E.P.; NETO, J.A. et al. Influência da dieta com diferentes níveis de lipídeo e proteína na resposta fisiológica e hematológica de reprodutores caprinos sob estresse térmico. Cienc. Agrotecnol., v.30, p.154-161, 2006.

SOUSA, R.S.; SOUSA, I.K.F.; PAULA, V.V.; BARRÊTO JÚNIOR, R.A. Alterações hematológicas de ovinos submetidos à implantação de cânula ruminal e orquiectomia. In: IX Congresso Brasileiro de Buiatria, Goiânia. Vet. Zootec., v.18, (Supl. 3), p.485-487, 2011.

STATISTICAL Analysis Sistem. SAS INSTITUTE. SAS. Cary, 2000. Software v.8.1.

VIANA, R.B.; BIRGEL JUNIOR, E.H.; AYRES, M.C.C. et al. Influência da gestação e do puerpério sobre o leucograma de caprinos da raça Saanen, criados no Estado de São Paulo. Braz. J. Vet. Res. Anim. Sci., v.39, p.196-201, 2002. 